\title{
Developing a HACCP-like system for improving animal health and welfare in organic egg production - based on an expert panel analysis
}

\author{
L. Hegelund ${ }^{\dagger}$ and J. T. Sørensen \\ Department of Animal Health, Welfare and Nutrition, Faculty of Agricultural Sciences, University of Aarhus, PO Box 50, 8830 Tjele, Denmark
}

(Received 7 December 2006; Accepted 6 April 2007)

\begin{abstract}
In the process of developing a generic Hazard Analysis and Critical Control Point (HACCP)-like system for securing animal health and welfare in organic egg production, an expert panel analysis was used to perform the initial hazard analysis. Eighteen advisers and researchers in organic egg production were included in the expert panel. In a series of four questionnaires, the expert panel first scored 34 health and welfare problems seen in Danish organic egg production. Based on scorings of severity and occurrence, 10 problems were selected for further analysis. The experts subsequently suggested and scored risk factors for those problems and finally suggested control points, alarm values indicating the need for corrective actions in order to control the risk factors and monitoring frequencies of these. The 10 selected problems were hunger, thirst, piling, crop impaction, blackhead, pasteurellosis, bone fractures, cannibalism, predators and red mites. A total of 154 different risk factors were suggested for these problems. The 41 risk factors which rated highest in a combined scoring of importance and occurrence were selected for further analysis. There was a high degree of consensus between experts when scoring both problems and risk factors. The level of consensus, as defined by an interquartile range $\leqslant 1$, was $79 \%$ to $100 \%$ when scoring the health and welfare problems (scale 1-5) and 77\% to 95\% when scoring the risk factors (scale 1-4). On average, 5.8 control points were suggested for every risk factor. Alarm values were often not detailed enough to be of practical significance and further analysis is needed in order to define these. The experts were highly diverse in their suggested monitoring frequencies and establishment of monitoring schemes should be part of developing the farm specific systems. An expert panel analysis based on questionnaires was a useful tool during the first steps of developing a HACCP plan, conducting a hazard analysis and suggesting control points. However, care should be taken regarding the panel's size and fields of expertise in order to assure that the panel fully covers the field of interest throughout the study. A further development of the hazard analysis into a farm-specific HACCP system would include assembling an on-farm HACCP team consisting of farmers and advisors for the practical application of control points, alarm values and monitoring schemes. The results from the fourth questionnaire would be useful as input for this work.
\end{abstract}

Keywords: expert panel, HACCP, welfare

\section{Introduction}

Organic egg production is struggling with problems compromising the health and welfare of the animals, as indicated by high rates of mortality (Hermansen et al., 2004) and high levels of feather pecking (Bestman and Maurer, 2006). The organic consumers as well as the organic organisations emphasise the importance of good animal welfare (Harper and Makatouni, 2002; International

\footnotetext{
†E-mail: Lene.Hegelund@agrsci.dk
}

Federation of Organic Agriculture Movements, 2006). The fact that some farms have serious problems while others seem to work fine suggests that management is an area which can be improved (Hegelund et al., 2006).

The Hazard Analysis and Critical Control Point (HACCP) system is a management tool developed to secure food safety. During the last decade, the HACCP concept has gained general acceptance in the food processing industry and is presently implemented by several authorities in among others like the EU, the USA, Canada and Australia (Ropkins and Beck, 2000). HACCP systems are based on 
Improving layer welfare in a HACCP-system, developed by expert panel analysis

prevention, by controlling the risk factors for any given (food) hazard. The HACCP system consists of seven principles. The first three principles include (1) defining the problem (the hazard) and defining and evaluating risk factors for the problem, (2) defining critical control points and (3) choosing alarm values for the critical control points. The succeeding principles are integration of the critical control points in a HACCP system, which includes (4) setting up schemes to monitor critical control points and establishing (5) corrective actions if alarm values are exceeded, (6) verification procedures to ensure that all procedures are performed according to plans and (7) documentation procedures for keeping records of all procedures (Food and Agriculture Organization, 2001). HACCP systems can be extensive and time consuming to produce (Baird et al., 2001), making construction of generic systems within specified production types desirable for many small-scale production facilities (Food Safety and Inspection Service (FSIS), 1997). Generic systems serve as guidelines for subsequent further development of a HACCP system tailored for a specific production facility (FSIS, 1997; Canadian Food Inspection Agency, 2005).

As a consequence of the wide application of HACCP systems, interest has arisen to adapt the HACCP system to the livestock production, also focusing on key issues other than securing food safety (Noordhuizen and Frankena, 1999). The advantage of using a system based on prevention rather than cure seems obvious when dealing with animal health and welfare. HACCP-like systems have recently been developed with the purpose of securing animal welfare and managing diseases, as for instance pre-slaughter stress in pigs (Von Borell and Schäffer, 2005), calf-rearing management (Boersema, 2006), quality assurance on dairy farms (Silva et al., 2006) and herd health management in organic pig production (Bonde and Sørensen, 2004). However, using the HACCP system to secure animal health and welfare poses different challenges than applying HACCP for food safety purposes. In the food industry, the risk factors (i.e. disease causing agents) are clearly defined physical entities (bacteria, metal pieces, etc.) which can be traced through the production chain. In contrast, risk factors for the development of welfare problems often comprise specific housing conditions or animal interactions which cannot be treated as yes/no entities. This leads to a central point of the HACCP development: defining and evaluating risk factors for the chosen problem. Often the lack of empirical knowledge of the importance of each risk factor reduces the possibility completely to control the problem within the frames of the farming system (Noordhuizen and Frankena, 1999). This is especially true for multicausal problems such as tail biting in pigs or cannibalism in poultry. Expert panel analyses can be used to analyse situations where empirical data are too scarce to perform traditional statistical analyses (Vose, 2000).

The purpose of this paper is to describe and discuss the development of a generic HACCP-like system, aimed at securing animal health and welfare in commercial organic egg production. The HACCP-like system is developed on the basis of an expert panel analysis.

\section{Methods}

Experts familiar with organic egg production systems were used to perform the first steps of an HACCP analysis, including defining the health and welfare problems, defining and evaluating risk factors for the problem, defining critical control points and choosing alarm values for the critical control points. The experts filled out a series of four questionnaires, where the design of each questionnaire was dependent on the answers of the previous questionnaire. The method has many similarities with a Delphi approach, which is frequently used in the human health-care sector (e.g. Keeney et al., 2001) but which has also been applied within animal husbandry and management, for a quantification of expert knowledge (Van der Fels-Klerx et al., 2000; Sørensen et al., 2002).

Although Delphi analyses are widely used, there are no standard definitions for consensus (Powell, 2003). In the present study, the level of consensus is measured using the interquartile range (IQR), with the following definitions: $\mathrm{IQR}=<0.5$ : strong consensus, $0.5<\mathrm{IQR}<=1$ : moderate consensus, IQR $>1$ : no consensus.

\section{Recruitment}

As a result of the expert panel, analysis is an aggregation of the experts' assessment of a given problem, where the choice of experts becomes highly important. To ensure that experts had the same field of expertise and the same cultural and legislative background, experts were included on the basis of two criteria. (1) Experts should be researchers and/or advisors with experience in on-farm welfare in commercial free-range or organic egg production systems. (2) Experts should be from EU countries geographically close to Denmark. To avoid bias, only one expert could be included per research institute. The aim was to include 15-20 experts in the panel. All correspondence was performed via e-mail and the experts were anonymous to each other.

Six key persons in Denmark, Sweden, Germany, The Netherlands and The UK were selected. The key persons suggested candidates for the expert panel and, in addition, the contacted panel candidates were asked to suggest other relevant candidates.

\section{Questionnaire sequence}

As explained below, the process of the expert panel analysis was a repeated sequence of preparing a questionnaire $(\mathrm{Q})$, sending it to the expert panel, collecting replies and preparing the next questionnaire based on these replies.

Questionnaire 1 (Q1). A list aimed to include the health and welfare problems seen in Danish organic egg production 
was assembled. Initially, the list included the primary causes of death seen in Danish organic egg production and behavioural deprivations caused by inability to perform natural behaviours (Johansen, 2003). Subsequently, four Danish researchers with experience in practical management and two poultry advisors from the Danish Agricultural Advisory Service were asked to add suggestions and comment on the list. This resulted in a list of 34 health and welfare problems seen in Danish organic egg production (Appendix A).

In Q1, the experts were asked to score each of the 34 problems according to how severe is it for the animal's welfare to be subjected to the problem ('severity') and how often an animal in the organic egg production is subjected to the problem ('frequency'). Severity and frequency were scored on a five-point scale: $5=$ very severe/very frequent, $4=$ severe/frequent, $3=$ moderate/regular, $2=$ less severe/ rare, $1=$ not severe/very rare.

Questionnaire 2 (Q2). The median values of severity and frequency were calculated for each problem and based on these scorings, the most important health and welfare problems were selected. The most severe (scoring 5) and most frequent (scoring 5) problems were selected first and then the most severe (scoring 5) and less frequent (from 4.5 to 1) problems were selected. To reduce the scope of the expert panel analysis, a maximum of 10 health and welfare problems were set to be the limit for the subsequent analysis.

In Q2, all experts received a spreadsheet with the selected health and welfare problems listed in the same chronological order and were asked to suggest risk factors for these problems.

Questionnaire 3 (Q3). Based on the replies to Q2, lists of risk factors for each problem were generated. The lists were edited with the purpose of ensuring that all risk factors were equally detailed. Risk factors with a high degree of similarity were merged and risk factors not compatible with organic regulations were deleted, e.g. beak trimming is prohibited according to organic regulations, so 'no beak trimming' is not accepted as a risk factor for 'cannibalism'.

To check for problems with response-fatigue when filling out the comprehensive spreadsheet, the number of suggested risk factor per problem was examined.

In Q3, experts were asked to score each risk factor with respect to how severe the risk factor is for developing the welfare problem (severity) and how frequent the risk factor occurs in the production (frequency). Severity and frequency were scored on a four-point scale: $4=$ severe/frequent, $3=$ moderate/regular, $2=$ less severe/rare, $1=$ not severe/ very rare.

Questionnaire 4 (Q4). After the panel had rated the risk factors, the median values of severity and frequency were calculated and risk factors were chosen based on their scorings. The aim was to include an average of 3-4 risk factors per problem, but imposing the criterion that all hazards have a minimum of one risk factor. Risk factors with the following scorings were selected: severity 4 and frequency $2-4$; severity 3.5 and frequency $3-4$; severity 3 and frequency 4.

In Q4, the experts were asked to list all possible control points in as much detail as possible for each risk factor and also suggest alarm values for each control point. Control points were defined as 'elements of the production that needed to be monitored (controlled) in order to prevent the risk factor from appearing', and alarm values as 'the values that separate good conditions from bad conditions'. Examples were given to the experts in order to clarify the explanation. For example, the risk factor for intestinal parasites 'insufficient cleaning of the outdoor area near the house, between flocks' could have the following control point and alarm values: change of top soil between flock: change of top $10 \mathrm{~cm}$ of earth in $0-15 \mathrm{~m}$ distance from pop holes.

\section{Results}

\section{Recruitment}

Thirty-two experts were contacted, and 18 accepted participation in the expert panel. They were from Denmark (4), Germany (3), the UK (3), Sweden (2), The Netherlands (2), Austria (1), Norway (1), Finland (1) and Switzerland (1). One expert was included after preparation of Q2, and therefore only participated in Q2 to Q4. While in one case, two experts cooperated in answering; they returned only one set of questionnaires and were registered as only one expert in the panel.

Questionnaires were prepared and sent out in May (Q1), June (Q2), July (Q3) and September (Q4) 2005. As the expert panel analysis progressed, the response rate dropped from 17 in the first two questionnaires to 12 in the third and 13 in the final questionnaire. Reminders were sent to experts not complying with the deadlines and the number of reminders increased from 3 in Q1, to 5 in Q2, 7 in Q3 and reached 19 in Q4. In Q4, six experts responded without reminders, four responded after the first reminder, and three responded after two reminders.

\section{Questionnaire 1}

Ten problems were selected for further analysis: hunger, thirst, piling, crop impaction, blackhead, pasteurellosis, bone fractures, cannibalism, predators and red mites (Table 1). Seventeen problems scored 4 in severity and 2 to 3 in frequency, and the remaining seven problems scored 2 to 3 in severity and 2 to 5 in frequency.

Consensus was reached in all selected problems when scoring severity (20\% strong and $80 \%$ moderate) and in eight of the selected problems when scoring frequency ( $20 \%$ strong and $60 \%$ moderate). Among the 24 problems that were excluded, there was consensus in 21 problems 
Table 1 Scorings of severity and frequency of the 10 selected health and welfare problems

\begin{tabular}{llcccccc}
\hline \hline & \multicolumn{3}{c}{ Severity } & & \multicolumn{3}{c}{ Frequency } \\
\cline { 3 - 4 } \cline { 5 - 6 } & $n$ & Median & IQR & & Median & IQR \\
\hline Health/welfare problem & & & & & & & \\
$\quad$ Predators & 17 & 5 & 1 & 17 & 3 & 1 \\
Cannibalism & 17 & 5 & 0 & 17 & 3 & 1 \\
Piling & 17 & 5 & 1 & 17 & 2 & 0 \\
Bone fractures & 17 & 5 & 1 & 17 & 2 & 2 \\
Crop impaction & 15 & 5 & 1 & 14 & 2 & 0.8 \\
Blackhead & 14 & 5 & 1 & 15 & 2 & 0.5 \\
Pasteurellosis & 15 & 5 & 1 & 16 & 2 & 1 \\
$\quad$ Hunger & 17 & 5 & 1 & 17 & 1 & 1 \\
Thirst & 17 & 5 & 0 & 17 & 1 & 1 \\
Red mites & 16 & 4 & 1 & 16 & 4 & 1.3 \\
\hline \hline
\end{tabular}

$n=$ number of experts scoring the problem; median=median scoring; $\mathrm{IQR}=$ interquartile range.

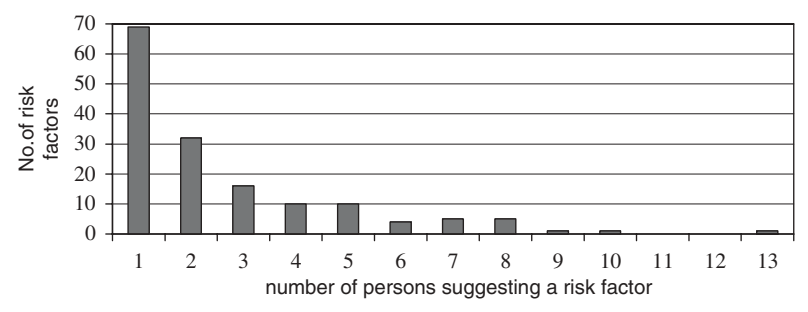

Figure 1 Distribution of number of risk factors suggested by between one and 13 experts in the panel.

when scoring severity ( $12.5 \%$ strong and $75 \%$ moderate) and in 19 when scoring frequency $(20.8 \%$ strong and $58.3 \%$ moderate).

\section{Questionnaire 2}

Q2 resulted in a total of 412 suggested risk factors including several doublets. After editing, the list of risk factors was reduced to 154 distributed on the following 10 health and welfare problems: predators (9), pasteurellosis (18), piling (13), hunger (20), blackhead (16), crop impaction (12), cannibalism (21), bone fractures (12), thirst (16), and red mites (17). On average, each risk factor was suggested 2.6 times. Sixty-nine of the 154 risk factors were suggested by one expert only (Figure 1).

Apparently, there were no problems with response-fatigue as the health and welfare problems getting the fewest suggestions from the experts were numbers four and six in the spreadsheet, while the first and ninth got the most suggestions.

\section{Questionnaire 3}

The list of 154 risk factors was scored by the expert panel and 41 risk factors fell within the selection criteria (Table 2): predators (3), pasteurellosis (3), piling (3), hunger (4), blackhead (2), crop impaction (1), cannibalism (8), bone fractures (4), thirst (7) and red mites (6). Seven of the selected 41 risk factors were suggested by only one expert in Q2.

There was consensus in 119 of the 154 risk factors when scoring severity ( $28.6 \%$ strong and $48.7 \%$ moderate) and in 137 when scoring frequency (34.4\% strong and $54.5 \%$ moderate). Among the 41 selected risk factors, consensus was reached in 39 when scoring severity (39\% strong and $56.1 \%$ moderate) and in 37 when scoring frequency $(29.3 \%$ strong and $61 \%$ moderate).

\section{Questionnaire 4}

Thirteen experts returned the questionnaire and the average response rate for the 41 risk factors was 86.9 (Table 3). A total of 390 suggestions referred to control points, resulting in 99 different suggestions when eliminating doublets (within and between risk factors) and control points not practically applicable by the producers in general management procedures. On average, 5.8 different control points were suggested for every risk factor. Alarm values were suggested in 381 of the answers and, of these, $44.6 \%$ were specific enough to be practically applicable. The remaining alarm values were less precise, including terms such as 'high' or 'good'. A monitoring frequency was suggested in 260 answers and $88.1 \%$ of these were detailed enough to be of practical significance, while the remaining answers included terms such as 'frequent' or 'regular'.

A wide range of control points were suggested, relating to different aspects of the production including caretaker routines/training (15), rearing conditions (7), behaviour (14), production (4), system (27), pasture (6), diet (11), diseases (7) and cleaning procedures (8), as exemplified in Table 4. The large number of control points reflects that some risk factors can be monitored using different types of control points, including both animal-based indicators and system-based indicators. For example, the risk factor for thirst 'animals too small to reach drinkers' can be controlled by checking either drinker height (at level with bird's back) or bird's posture when drinking (stretching neck). In this case, the exact choice of control points should be selected to suit the management in the best possible way when developing the farm-specific systems. Also, some risk factors must be monitored using information from more than one control point, for instance, the risk factor for cannibalism 'physiological stress at onset of lay' would require monitoring of 'bird weight', 'egg production', 'feed plan' and 'light programme'. Other risk factors were easier to monitor, resulting in uniform suggestions from the panel, e.g. the risk factor for predators: 'insufficient closure of pop holes', where all experts agreed on 'check closure of pop holes every evening'.

In some cases, a considerable variation was seen in the suggested alarm values for the same control point. It was most pronounced in the suggested alarm values for control point 'stocking density' in order to avoid 'piling' which were 4,5 and 6 hens $/ \mathrm{m}^{2}$. However, most differences were seen in monitoring frequencies, e.g. in the control point 'checking 


\begin{tabular}{|c|c|c|c|c|c|c|c|}
\hline & \multirow[b]{2}{*}{ Risk factor } & \multicolumn{3}{|c|}{ Severity } & \multicolumn{3}{|c|}{ Frequency } \\
\hline & & $n$ & Median & IQR & $n$ & Median & IQR \\
\hline \multicolumn{8}{|l|}{ Hazard } \\
\hline \multirow[t]{3}{*}{ Predators } & Insufficient closing of pop holes at night & 12 & 4 & 1 & 12 & 2 & 1.3 \\
\hline & Security of house/holes in the house & 11 & 4 & 0.5 & 11 & 2 & 1.5 \\
\hline & Poor fencing & 12 & 4 & 1 & 12 & 3 & 0.5 \\
\hline \multirow[t]{3}{*}{ Pasteurellosis } & No disease identification when mortality rises & 8 & 4 & 0.3 & 8 & 2.5 & 1 \\
\hline & No vaccination of 'high risk' flocks & 7 & 4 & 1 & 6 & 2 & 0.8 \\
\hline & Poor clean out between flocks & 8 & 4 & 1 & 8 & 2.5 & 1 \\
\hline \multirow[t]{3}{*}{ Piling } & High stocking density & 12 & 3.5 & 1 & 11 & 3 & 1 \\
\hline & Nervousness/fearful hens & 12 & 4 & 1 & 12 & 2 & 0.6 \\
\hline & Rearing: insufficient habituation to stressors & 12 & 4 & 1 & 12 & 3 & 0 \\
\hline \multirow[t]{4}{*}{ Hunger } & Malfunctioning feeder system & 12 & 4 & 1 & 12 & 2 & 0 \\
\hline & Electricity failure & 12 & 4 & 1 & 12 & 2 & 1 \\
\hline & Pathology (e.g. crop distension) & 11 & 4 & 0.5 & 11 & 2 & 1 \\
\hline & Illness/injury preventing movement/eating & 12 & 4 & 0 & 12 & 2 & 1.3 \\
\hline \multirow[t]{2}{*}{ Blackhead } & Poor pasture management & 10 & 3.5 & 1 & 10 & 3 & 0 \\
\hline & Poor clean out between flocks & 9 & 4 & 1 & 9 & 2 & 1 \\
\hline Crop impaction & Feed deficiency & 11 & 4 & 1.5 & 11 & 2 & 1 \\
\hline \multirow[t]{8}{*}{ Cannibalism } & Poor diet & 12 & 4 & 1 & 12 & 2.25 & 1 \\
\hline & No elevated perches/no adequate use & 11 & 4 & 2 & 11 & 2 & 1 \\
\hline & Low stimulation & 12 & 4 & 0.3 & 12 & 3 & 1 \\
\hline & No action at first signs of cannibalism & 12 & 4 & 0 & 12 & 2.25 & 1 \\
\hline & Occurrence of wounds & 12 & 4 & 0 & 12 & 2 & 0.6 \\
\hline & Feather pecking & 12 & 4 & 1 & 12 & 3 & 0.3 \\
\hline & Poor management of pullets in rearing & 12 & 3.5 & 1 & 12 & 3 & 1 \\
\hline & Physiological stress at onset of lay & 12 & 4 & 1 & 12 & 3 & 0 \\
\hline \multirow[t]{4}{*}{ Bone fractures } & Poor/rough handling during catching & 11 & 4 & 0.5 & 11 & 3 & 1 \\
\hline & Rough handling during production period & 11 & 4 & 0.5 & 11 & 2 & 0.5 \\
\hline & Poor diet & 11 & 4 & 0.5 & 11 & 2 & 0.5 \\
\hline & Equipment broken or with sharp edges & 11 & 4 & 1 & 11 & 2 & 0 \\
\hline \multirow[t]{7}{*}{ Thirst } & Not enough drinkers & 12 & 4 & 1 & 12 & 2 & 1 \\
\hline & Malfunctioning water system (pipes, drinkers) & 12 & 4 & 0 & 11 & 2 & 0 \\
\hline & Insufficient supply (e.g. pressure, electricity) & 12 & 4 & 0.3 & 12 & 2 & 1 \\
\hline & Thermal stress & 12 & 4 & 0.3 & 12 & 2 & 1.3 \\
\hline & Poor accessibility of water (design) & 12 & 4 & 1 & 12 & 2 & 1 \\
\hline & Animals too small to reach drinkers & 12 & 4 & 0.3 & 12 & 2 & 1 \\
\hline & Illness/injury preventing movement/drinking & 12 & 4 & 1 & 12 & 2 & 1 \\
\hline \multirow[t]{6}{*}{ Red mites } & High temperatures & 11 & 4 & 1 & 11 & 3 & 1 \\
\hline & Poor house and furniture design & 11 & 4 & 0 & 11 & 3 & 0 \\
\hline & Insufficient cleaning/disinfection between flocks & 11 & 4 & 0 & 11 & 3 & 1 \\
\hline & Poor hygiene during the production period & 11 & 4 & 1 & 11 & 3 & 1 \\
\hline & Delayed treatment if number of mites rises & 11 & 4 & 1 & 11 & 3 & 0 \\
\hline & Underestimation of consequences if number of mites rises & 11 & 4 & 1 & 11 & 3 & 1 \\
\hline
\end{tabular}

$n=$ number of experts scoring the risk factor; median = median scorings; IQR = interquartile range of scorings.

the house for holes' to avoid access of 'predators', suggested monitoring frequency included 'daily, 'weekly', 'every 6 months' and 'every year'.

\section{Discussion}

The health and welfare problems used as a starting point for the questionnaire series correspond quite well to the health problems seen in European organic egg production, as reviewed by Thamsborg et al. (2004) and Bestman
(2004), and problems associated with performing natural behaviour as described by Waiblinger et al. (2004); however, some differences are noticeable. Some diseases included in the reviews were not included in Q1 and although the agreement between the two reviews is limited to only five diseases, one of those, coccidiosis, is not included in Q1. Coccidiosis was omitted because it is consistently controlled by vaccines and is predominately considered a problem in the rearing units (Johansen, 2003), while the present system is developed for egg production. In addition, feather pecking was excluded from the list 
Improving layer welfare in a HACCP-system, developed by expert panel analysis

Table 3 Response rate and number of specific answers from the experts in the panel, in questionnaire 4

\begin{tabular}{|c|c|c|c|c|c|}
\hline & Total & Average & Minimum & Maximum & s.d. \\
\hline Total number of suggestions in Q4 & 462 & 11.3 & 7 & 13 & 1.7 \\
\hline $\begin{array}{l}\text { No. of suggestions including control points } \\
\text { No. of different control points }\end{array}$ & 390 & 9.5 & 1 & 13 & 2.6 \\
\hline - Not excluding doublets between risk factors & 237 & 5.8 & 1 & 14 & 3.3 \\
\hline - Excluding doublets within and between risk factors & 99 & & & & \\
\hline No. of suggestions including monitoring frequencies & 260 & 6.3 & 1 & 13 & 2.6 \\
\hline - No. of specific monitoring frequencies & 229 & 5.6 & 1 & 13 & 2.6 \\
\hline No. of suggestions including alarm values & 381 & 9.3 & 1 & 13 & 2.6 \\
\hline - No. of precise alarm values & 170 & 4.1 & 0 & 8 & 2.1 \\
\hline
\end{tabular}

Table 4 Examples of problems with associated risk factors and control points

\begin{tabular}{lll}
\hline \hline Problem & \multicolumn{1}{c}{ Risk factor } & \multicolumn{1}{c}{ Control point } \\
\hline Bone fractures & Poor/rough handling & Carry hens on both legs \\
Cannibalism & Poor management of pullets in rearing & Visit at rearer \\
Thirst & Not enough drinkers & Aggression by drinkers \\
Cannibalism & Physiological stress at onset of lay & Start of egg production \\
Hunger & Malfunctioning feeding system & Feeding line running \\
Pasteurellosis & No disease identification & Daily/weekly mortality \\
\hline \hline
\end{tabular}

although it is probably one of the most used indicators of welfare problems in organic egg production (e.g. Bestman and Maurer, 2006). This decision was taken because feather pecking, sometimes being a precursor of cannibalism (Kjaer, 1999; Thamsborg et al., 2004), would be controlled as part of preventing cannibalism. On the other hand, 12 health and welfare problems not mentioned as health or welfare problems in the reviews were included in the questionnaire. Three of these (hunger, thirst and crop impaction) were subsequently selected for further analysis. In conclusion, the risk of missing problems such as thirst, which is related to impaired system maintenance and therefore unlikely to gain attention in research papers, and the lack of empirical evidence on the severity of the problems, emphasises the value of an expert panel for scoring and thereby selecting problems for further analysis instead of basing the selection solely on literature reviews.

Analysis of the responses indicates that the expert panel might be undersized. Seventeen percent of the selected risk factors in Q3 were suggested by only one expert in Q2. This appears to be a relatively low degree of overlap between experts and a possible consequence is an increased risk of missing important risk factors. The problem is most obvious in the third and fourth questionnaire where the response rate dropped to $30 \%$. A considerable drop in response rate is not unusual in studies comprising a series of questionnaires (Mullen, 2003). It is probably caused by the long duration of the analyses and the anonymity of the experts, as they consequently feel less motivated or obligated. Studies show that a very close follow-up on responses can improve the response rate (Keeney et al., 2006). Consequently, including more experts in the panel may have resulted in a more comprehensive analysis of the problem areas and compensated for missing expertise due to falling response rates.

Due to the considerable scope of the topic 'health and welfare in organic egg production', the experts need to cover many different subjects which increases the risk of lacking knowledge in certain areas. However, throughout the questionnaire there is generally a high level of consensus between the experts both regarding scorings of problems and scorings of risk factors. The high level of consensus indicates that the choice of experts meets the requirements set for the expert panel and sufficiently fulfils the first part of the analysis. The experts base their knowledge on comparable organic systems and they focus on the same risk factors for controlling health and welfare parameters in productions. Still, there is a tendency for the total percentage of consensus (including strong and moderate) to be lower when scoring severity in Q3 compared with Q1, indicating more disagreement when scoring risk factors; especially, when considering that changing the scale from Q1 to Q3 increases the chance of a higher level of consensus in Q3.

In the fourth questionnaire, the experts suggested many different control points. Some of this variation is caused by the multicausal nature of the health and welfare problems, resulting in a need for multiple control points when managing the problems. But also the experts' preferences for system-based $v$. animal-based indicators would result in 
different control points. The experts were also diverse in their suggested alarm values, but whether this apparent diversity would lead to low consensus is not investigated in a rating questionnaire. The most obvious problem was the lack of specific alarm values to some of the control points. A general reluctance to set alarm values probably reflects the fact that many control points in the production have a continuous range of values, ranging from 'perfect condition' to 'unacceptable', and setting a specific value separating 'good' from 'bad' is very difficult. Consequently, the stated alarm values do not reflect a thorough evaluation of critical limits, emphasising the need for a separate analysis to achieve specific alarm values for the HACCP system. It is unlikely that simply rephrasing the questions would result in more specific answers, as all experts were able to supply specific alarm values to some of the control points. Still, the suggested control points and alarm values can be used as input for developing the farm-specific HACCP systems.

The combination of lack of practical management experience by the experts and the lack of information of the specific housing conditions probably made it difficult for the expert panel to agree on monitoring frequencies. Consequently, the specification of monitoring frequencies should be a part of developing the farm-specific systems.

In conclusion, using an expert analysis to develop a generic HACCP system has led to selection of important problems and risk factors. In addition, a number of possible control points with related alarm values and monitoring schemes were suggested. A further development of the hazard analysis into a farm-specific HACCP system would include assembling an on-farm HACCP team consisting of farmers and advisors for the practical application of control points, alarm values and monitoring schemes. Attention should be focused on the selected risk factors and the results from the fourth questionnaire can be used as input for selecting appropriate control points. The alarm values should ensure that the value targeted as the appropriate level of each risk factor is not underestimated, however, a separate analysis is necessary to define this level.

\section{Acknowledgement}

We thank all the participating experts.

\section{References}

Baird DR, Henry M, Liddell KG, Mitchell CM and Sneddon JG 2001. Postoperative endophthalmitis: the application of hazard analysis critical control points (HACCP) to an infection control problem. The Journal of Hospital Infection 49, 14-22.

Bestman M 2004. Health in organic laying hens - facts and fairy tales. Proceedings of the 2nd SAFO Workshop, Witzenhausen, Germany.

Bestman M and Maurer V 2006. Health and welfare in organic poultry in Europe: state of the art and future challenges. Proceedings, European Joint Organic Congress, Odense, Denmark.

Boersema SJ 2006. Applications of HACCP-principles to calf rearing management. In Workshop on HACCP-like applications on dairy farms. The concept and principles of HACCP (ed. J Noordhuizen and JC Silva). Workshop during the 14th World Buiatrics Congress, Nice, France.
Bonde M and Sørensen JT 2004. Herd health management in organic pig production using a quality assurance system based on Hazard Analysis and Critical Control Points. NJAS - Wageningen Journal of Life Sciences 52, 133-143.

Canadian Food Inspection Agency 2005. Food safety enhancement program HACCP generic models. Retrieved September 12, 2006, from http:// www.inspection.gc.ca/english/fssa/polstrat/haccp/modele.shtml.

Food and Agriculture Organization 2001. Hazard Analysis and Critical Control Point (HACCP), system and guidelines for its application. Annex to CAC/RCP 11969, Rev. 3 (1997) In Codex alimentarius-food hygiene-basic texts, second edition. The Secretariat of the Joint FAO/WHO Food Standards Programme, FAO, Rome.

Food Safety and Inspection Service 1997. Current technical assistance and information: pathogen reduction/hazard analysis and critical control points. Generic HACCP models. Retrieved October 10, 2006, from http://www.fsis. usda.gov/oa/haccp/haccpup1.htm .

Harper GC and Makatouni A 2002. Consumer perception of organic food production and farm animal welfare. British Food Journal 104, 287-299.

Hegelund L, Sørensen JT and Hermansen JE 2006. Welfare and productivity of laying hens in commercial organic egg productions systems in Denmark. NJAS Wageningen Journal of Life Sciences 54, 147-155.

Hermansen JE, Strudsholm K and Horsted K 2004. Integration of organic animal production into land use with special reference to swine and poultry. Livestock Production Science 90, 11-26.

International Federation of Organic Agriculture Movements 2006. The St Paul declaration. First IFOAM International Conference on Animals in Organic Production, University of Minnesota, St Paul, Minnesota, USA, 23-25 August 2006. Retrieved October 20, 2006, from http://www.ifoam.org/press/positions/ St.Paul_Declaration.html.

Johansen NF 2003. Driftsvejledning for økologisk ægproduktion [Management guide for organic egg production]. GP-Tryk, Grenaa, Denmark.

Keeney S, Hasson F and McKenna HP 2001. A critical review of the Delphi technique as a research methodology for nursing. International Journal of Nursing Studies 38, 195-200.

Keeney S, Hasson F and McKenna H 2006. Consulting the oracle: ten lessons from using the Delphi technique in nursing research. Journal of Advanced Nursing 53, 205-212.

Kjaer JB 1999. Feather pecking in laying hens: Genetic and environmental factors. PhD thesis, Danish Institute of Agricultural Sciences.

Mullen PM 2003. Delphi: myths and reality. Journal of Health Organization and Management 17, 37-52.

Noordhuizen JPTM and Frankena K 1999. Epidemiology and quality assurance: application at farm level. Preventive Veterinary Medicine 39, 93-110.

Powell C 2003. The Delphi technique: myths and realities. Journal of Advanced Nursing 41, 376-382.

Ropkins K and Beck AJ 2000. Evaluation of worldwide approaches to the use of HACCP to control food safety. Trends in Food Science and Technology 11, 10-21.

Silva JC, Noordhuizen J and Gingão P 2006. VACQA - veterinary advice and coaching in quality assurance on dairy farms. Retrieved October 24, 2006, from http://www.vacqa-international.com.

Sørensen JT, Østergaard S, Houe $H$ and Hindhede J 2002. Expert opinion strategies for milk fever control. Preventive Veterinary Medicine 55, 69-78.

Thamsborg SM, Roderick S and Sundrum A 2004. Animal health and diseases in organic farming: an overview. In Animal health and welfare in organic agriculture (ed. M Vaarst, S Roderick, V Lund and W Lockerez), pp. 227-252. CABI Publishing, Wallingford, UK.

Van der Fels-Klerx HJ, Horst HS and Dijkhuizen AA 2000. Risk factors for bovine respiratory disease in dairy youngstock in The Netherlands: the perception of experts. Livestock Production Science 66, 35-46.

Von Borell E and Schäffer D 2005. Legal requirements and assessment of stress and welfare during transportation and pre-slaughter handling of pigs. Livestock Production Science 97, 81-87.

Vose D 2000. Risk analysis. A quantitative guide, 2nd edition. Wiley, New York. Waiblinger S, Baumgartner J, Kiley-Worthington M and Niebuhr K 2004. Applied ethology: the basis for improved animal welfare in organic farming. In Animal health and welfare in organic agriculture (ed. M Vaarst, S Roderick, V Lund and W Lockerez). CABI Publishing Wallingford, UK. 
Improving layer welfare in a HACCP-system, developed by expert panel analysis

\section{Appendix A}

Health and welfare problems in commercial Danish organic egg production

The 10 selected health and welfare problems are indicated by bold letters

Infectious bronchitis

Erysipelas (inf. with E. rhusiopathiae)

Fowl colera (pastaurellosis)

Escherechia coli infection

Salpingitis

Blackhead (Histomoniasis)

Bone fractures

Foot pad dermatitis

Red mites (Dermanyssus gallinae)

Intestinal nematodes (e.g. Ascaridia galli)

Crop impaction

Hunger

Thirst

Negative energy balance

Malnutrition

Heat stress

Cold (frost)

Inappropriate light

Dust

Ammonia

Predator attacks

Cannibalism/vent pecking

Piling of birds resulting in suffocations

Inactivity (no stimulation)

Fearfulness

Aggression

Inability to perform natural behaviours:

- foraging behaviours

- mother/chicken interactions

- sexual behaviours

- nesting behaviours

- comfort behaviours

- explorative behaviours

- hide/escape from aggressions

- hierarchical interactions 